\title{
Consideration of Individual Differences: Activation vs. Inactivation
}

\author{
Shirin S. AlOdwan \\ Faculty of Education, Al-Ain University, \\ Al Jimi, Near Al Ain Municipality, Al Ain, \\ Abu Dhabi, United Arab Emirates
}

DOI: https://doi.org/10.36941/jesr-2022-0053

\begin{abstract}
The present research threw light on a number of issues related to personalization. Furthermore, an attempt was made to cast light on some wrong practices performed by teachers in their classes that negatively influence the educational process and compromise individual differences. In order to answer the research's questions and yield results, the qualitative descriptive method was employed. Having reviewed the theoretical literature, the effective way of considering individual differences was revealed. Moreover, having interviewed 20 teachers, I found the factors leading teachers to make errors regarding personalization, causing the latter not to accrue benefits. Accordingly, teachers were categorized in three groups: First: Teachers who do not perform what they disbelieve in, causing the practices not to accrue any benefits; Second: Teachers who are immersed in normative practices but ignore benefits; and Third: Teachers who consciously consider individual differences, as well as study and analyze students' patterns but increase rather than decrease those differences. Furthermore, appropriate solutions were presented to address those errors and to reach useful practices regarding personalization. Based on the results, a number of suggestions and recommendations were given which could help address personalization-related problems. Real observations, scientific discussions and long conversations were objectively made with a number of teachers. Whatever presented in this study was based on my observation from teachers' plans and some of their courses. I also monitored students' development and academic achievement. Over our discussions, teachers frequently asked "what is the problem?!" They put the blame on learners and sporadically on the social environment in which students grew up. They also sometimes considered families to be accountable in this regard. Rarely ever can a wise teacher be found to attribute the problem to his method and thus make systematic and insightful, not experiential and arbitrary, evaluation and correction. Furthermore, an effective teacher assumes full responsibility for his work and knows his class is part of a larger society. Therefore, he or she should not expect the best in everything, but he or she should let their holy profession alone create a perfect society. The more a teacher notches success and be sincere in his or her work, the closer we will be to a mature, effective and productive society, though the teacher may not realize that. Finally, I would emphasize we must change our expectations before our practices or our changes will accrue no benefits. Moreover, we must determine our needs in such a way that suit our students. We should not imitate others' practices without understanding how effective they will be in our classes and their current circumstances. Most importantly, a student should feel he or she is really actualizing himself or herself at any moment, and is acquiring new knowledge and skills after each class.
\end{abstract}

Keywords: individual differences, activation, inactivation 


\section{Introduction}

From the outset of history, humans perceived they are different. Difference is Allah's tradition on the earth. All powerful Allah says: "And of His signs is the creation of the heavens and the earth, and the diversity of your languages and colors. Surely, in this are signs for those of sound knowledge" (ArRum, 22).

The development of earth, civilizations, countries and human societies would not have taken place if humans had no different tendencies, abilities, capabilities and characteristics. In this regard, Asma'i in Majma' Al-Amsal argues: "Humans are in peace as long as they are different; they would extinct if they were identical."

Therefore, differences have been a constant reality ever since Allah created the universe. Having perceived these differences, humans started developing their lives accordingly. In his second book, Republic, Plato divided humans into three categories according to the differences between them. He considered the individual characteristics (physical, psychological and mental) that distinguish one category from the other. He pointed out that individuals differ from each other in terms of their dispositions, abilities and competencies. Aristotle, however, discussed the mental and moral differences between groups, individuals and genders. Also Farabi shed light on human differences in language abilities.

Prophet Mohammad (may Allah blessing and peace be upon him), as cited in Sahih Muslim, purports: "Do not speak to a group about something that goes beyond their understanding, because that would be regarded as seducement for some of them.” Therefore, should education aim at making some changes in the learner's behavior (Dakhl Allah, 2015), it has to consider the differences in learners as humans. Furthermore, should education aim at qualifying the individual to become effective in life, the teacher has to consider the characteristics of his learners by adapting the course to the individual differences between students.

Hence, it is normal for students in a class to have different abilities. A successful teacher considers these differences, however. A teacher is not to eliminate those differences but should make them more manifest to determine the appropriate practices for each level. The latter point shows the essence of personalization. We must differentiate between individual differences and personalization. We will do so in the Research Terms section. Here we should point out that some teachers find difficulties with personalizing or do so in such a way that cannot achieve the desired goal.

\section{Research Problem}

It is now self-evident in education that a capable teacher should consider the individual differences in students. Moreover, adopting a single method for teaching is no longer fruitful (Sakal \& Khalifeh, 2017). Therefore, a teacher must familiarize himself or herself with different aspects of these differences, including the psychological, physiological and mental aspects, among others. Also his or her teaching must be based on those characteristics, in order to make the desired change.

Although all these points are now self-evident, education in many schools is still facing the following obstacles:

- A teacher may try to act based on individual differences, though they do not understand how important those differences are. He or she does so just because individual differences are among the necessary things to be considered in modern education and are a criterion by which to evaluate a teacher;

- A teacher may understand the importance of individual differences and try to act accordingly, however, he or she does so superficially. He perhaps imitates what is commonplace in teachers' community and the modern strategies they employ, believing himself to be in compliance with modernity and educational advancement. Yet he does not investigate and analyze the characteristics of his students, nor does he truly know how 
effective a certain method is and how it influences learners; and

- A teacher may understand the importance of individual differences and the necessity of acting based on them. He or she may act on those differences after analyzing students' characteristics. Nevertheless, he deals with individual differences in such a way that they become more significant and persistent, not the reverse.

These negative points are dangerous in that they suppress learners' spirit of challenging and their ambitions. It is like students are told to remain in one position as it is the appropriate condition for them.

Indeed, there are many efficient teachers who perceive the effectiveness of personalization and know how to boost students' ambitions and creativity and how to enhance their self-confidence. In this study, I do not aim to deny that there are some minority teachers who admire the mere traditional method and who do not believe in the effectiveness of personalization and acting on it. Instead, in this research I want to throw light on the mistakes made in dealing with individual differences, which cause those differences to become more significant.

Of course, a teacher cannot eliminate learners' inborn individual differences but can minimize the differences in students' productivity and interaction with the subject taught. In fact, this is the role of the teacher.

\section{Research Questions}

Most teachers are concerned with individual differences, however, they make a mistake in practice. What leads a teacher to be concerned superficially with this issue without actively acting based on it? In this research, we will answer the following questions:

- How to effectively, and away from imitation, act based on individual differences in education?

- What are the causes that lead teachers to make these mistakes?

- How to address mistakes that teachers make in regard to taking into account individual differences?

\section{Research Objectives}

This research aims to throw light on a real problem we are facing in schools: taking into account individual differences. This is an obstacle for the teacher and requires effort and preparation from him. A teacher in many cases makes an effort to personalize, but his effort yields no result. Therefore, an attempt has to be made so that the teacher's effort be fruitful. There are several reasons for this problem that we will illuminate and discuss in this research.

\section{Research Significance}

It is natural for students in one class to have different capabilities. In other words, although students have some similar characteristics, they differ from each other in the degree to which they have each characteristic. However, a successful teacher takes these differences into account. It is not appropriate for a teacher to eliminate these differences but must illuminate the differences so as to determine which practices are appropriate for each person.

In order to reach an effective education, we have to personalize in a proper, healthy method. In the $21^{\text {st }}$ century, personalization undoubtedly takes precedence in the teaching profession. The ultimate goal of any practice is to accrue a benefit. Therefore, if personalization accrues no benefit, there has to be a problem in this regard. In this research, we want to shed light on this disturbance. 


\section{Research Terms}

An increasing number of definitions have been given about individual differences between students. Although various, the definitions suggest the same meaning. That is, all these definitions concern the physical, mental, emotional and personality differences between individuals. An effective, appropriate learning takes into account and is in compliance with this fact.

\subsection{First: Individual differences}

Some consider individual differences to be deviations in different attributes from group average (Sakal \& Khalifeh, 2017). Others, however, regard individual differences as the characteristics that distinguish one individual from the other. Such characteristics may concern one's body or social behavior (Adas, 1998). The most obvious physical individual differences are height, weight and voice, which are manifest and can be noticed. Many other differences also exist which are perceptually and emotionally peripheral.

Moreover, individual differences are defined as "individual deviations from the group average" (Khezri, Sheikh, 1982). Put it simply, individual differences distinguish one individual from the other.

\subsection{Second: Personalization}

It refers to the ways, methods or practices that a teacher employs to satisfy the individual differences needs of students or to adapt these practices in such a way as to be in line with those differences. Furthermore, personalization refers to the development of activities that take into account the fact that students have different abilities. These activities allow students to interact in such a way that suits their abilities.

\section{Research Method}

In this study, the Critical Theory has been adopted. This theory can be used in qualitative educational research and studies. The Critical Theory is among the most recent research paradigms in educational and social sciences. The Frankfurt School, Germany, employed this theory to discover the reality of, and gain a clear understanding about, social phenomena. The Critical Theory has helped us reach facts, data and generalizations that in turn raised our understanding about social and educational phenomena.

\section{Instrument}

The instrument comprised a set of standards set by the researcher to investigate the degree to which individual differences are considered. Standards include planning, raising questions, categorization of the classroom into strong, moderate and weak, homework correction, and use of reinforcement. To this end, a sample of 50 teachers were contacted via email and were informed about my desire to meet them in the classroom. They were also informed that the meeting was to perform the study on individual differences.

Some previous studies investigated individual differences, such as:

A study by Ahmad and Musa (2019) investigated the individual differences between males and females in social skills. Participants were university students from Libya. The scores of males and females on social skills were found to have significant differences, with males showing greater scores.

Another study by Daum (2017) was conducted to identify the most important teaching methods, from the viewpoint of physical education teachers, for adjusting to students' individual differences as a function of gender and field of study. The study also aimed to identify the differences in those teaching methods. Statistically no significant differences were found between the variables of the 
study.

\section{First Issue:}

- The importance of highlighting individual differences in education:

Individual differences are so important in the field of education and learning, such that understanding them can help in:

1. Preparing and planning for the course in such a way that conforms to students' contradictory abilities, talents, tendencies and needs;

2. Including many extracurricular activities and programs that take into account the contradictory levels of students. Such programs include talent support, cultural clubs, and scientific competitions;

3. Guiding students to choose the specializations that are suitable to their abilities, talents and tendencies;

4. Choosing the most appropriate teaching methods and extracurricular activities and programs; and

5. Helping the teacher to perform his role as an educational leader.

\section{- Personalization:}

Scientists have presented a number of teaching models that take into account the individual differences between learners:

1. The traditional model, which includes two secondary models:

- Enrichment model

- Acceleration model

2. Mastery learning, which adopts the theories of behavioral learning in general and Bloom's taxonomy in particular; and

3. Mixed teaching model, which is based upon the principles of Skinner's operant learning as well as Keller's personalized system of instruction (Keller Plan). This model aims to eliminate the traditional method which involves certain books. Instead, this method involves lectures but also considers other aspects such as students' abilities. Moreover, this method does not settle for only one book. It also requires stronger students to help their weaker peers. Keller believes his model mitigates the gap between students' individual differences in education (Reymawi, 1994).

- The importance of personalization in education:

It is very necessary to personalize, and the teacher assumes the major responsibility in this regard. Personalization helps achieve several primary ends in teaching and learning. To illustrate, it helps to call attention to different educational levels, thus increasing the educational output, decreasing the educational discrepancies, and achieving the desired levels by students. Also in this case, the different needs of a large number of students in a single class will be satisfied (Mohammad Kamel, 1996).

\section{Second Issue: Active vs. Inactive Practices}

Modern educational standards require the teacher to consider the individual differences between students. Teachers indeed learn this skill in teacher preparation programs as well as professional development programs, where they perceive the need for, and the ultimate goal of, this practice. In practice, however, many teachers make a mistake so that the individual differences are not dealt with in such a way as to achieve the desired goal. Instead, entirely the reverse result may occur.

Unfortunately, the field of education is sometimes used to display talents, capabilities and amazing models, to the point that the surface of education takes precedence and, either purposefully or not, the desired goal is forgotten. One example includes when a teacher gives priority to performing a strategy without considering whether the strategy is appropriate for students' characteristics, levels, tendencies, and individual differences. Nor does he think about the real improvement that this strategy can make for students. 
In this research, we will categorize the wrong practices under three headings. We presume that all teachers are knowledgeable about the theoretical aspect of individual differences between students. Yet we presume that mistakes are made in performance, for several reasons and among the following groups:

\section{First: The teacher who performs what he does not believe in}

Here, I want to devote some time to discussing the claims of some teachers who consider the teacher, not the student, to be the focus of educational process. They believe the teacher is to teach, explain and describe, and the student is to receive the lesson prescribed for him or her. This method is more beneficial, they argue, for the student than learning alone and wasting the class time as he or she wishes to. They believe this method is easier for the teacher, too. Yet they do not believe what they clearly claim! Why?!

This is because they have to meet the standards and satisfy the demands of modern education. It is now mandatory in all schools of the UAE to consider the individual differences. So imagine how this practice will be like? Such teachers basically refuse this principle but adhere to it superficially and just because their profession so requires.

For example, one kindergarten teacher presented three different activities to her students. Activity (a) required students to write down a letter in a certain cell on the page; activity (b) required students to look for the letter in a group of randomly spread letters; and activity (c) required students to make the letter using foam clay. Although only four students in the class were able to play with foam clay, some students refused to write down the letter as they wanted to join group (c). Therefore, as the teacher found students to be inharmonious with the activities, she decided to cancel all the three activities. Then she asked students to sit down on the carpet and look at the smart board. She again displayed the letter with the words and figures.

In our discussion, she argued she primarily tried to consider the individual differences but decided, as soon as students' behavior got worse, to perform the alternative plan. In fact, she inappropriately considered the individual differences, thus finally cancelled the activities and became the center of attention.

Assume this teacher to have provided any of her students with a task that satisfies his or her need and thus considered students' tendencies and areas of interest, especially in this stage of life. In this case, would not her teaching be more influential for students and the latter be more harmonious with the subject taught?

This was only one example and does not apply to all. This example showed how a teacher can perform a practice in which a teacher does not believe. Noteworthy, after my discussion with the teacher and asking her to answer some questions, it became apparent that she actually preferred to prescribe directly something to students over having them involved in different activities. It is also worth mentioning that teachers' professional development should aim at changing or enhancing teachers' viewpoints rather than their practices.

Similarly, some may successfully take educational tests and easily get the teaching license; however, tests will make no significant change in the method they employ. Therefore, a teacher should take part in continuous training courses and workshops which show him or her real or virtual cases. These cases can pose some problems and the would-be teacher should work out the solution after considering the problem. Otherwise, there would be no benefit from personalization if teachers remain as they are and if learners' characteristics are not analyzed and their various needs are not satisfied.

Second: The teacher who gives paramount importance to performing a practice than achieving the educational goal:

There are some teachers adopting modern and ever-developing educational forms, methods and approaches; every day we hear the names of new approaches. These teachers so much cling to those modern methods that the latter, not the credit or the course itself, have become the ultimate goal. Nonetheless, some believe we should not distinguish between the method and the course as there is of course a strong association between the two. Yet nothing is more important than achieving the 
educational goals. Therefore, when the desired goals are not achieved, a teacher should change or evaluate the practice but the objectives should not change, so as to be harmonious with a certain practice.

Having an appropriate knowledge in his or her field, wisely managing issues, and being professionally sincere, a teacher can overcome the above mentioned obstacles. That is, after performing each practice, such a teacher should evaluate his or her performance, think about the outcome, and analyze students' performance. By doing so, the teacher can realize whether he or she performed appropriately or not.

Nevertheless, a teacher should have some freedom to manipulate the methods and strategies in such a way that suit his or her students. It is not appropriate for the school administration to adopt a certain method and oblige teachers to perform this method, since a teacher better knows his or her students and the methods that are useful for them.

For example, a group of teachers were forced to perform the strategies of active learning (Kegan) in all courses. Over the year, the school administration provided professional development credits regarding these strategies. Some teachers, however, believed these strategies to be convenient only for information-based subjects, not for skill-based subjects such as language. This is because this method does not consider how deeply a piece of information is given, nor does it show how a skill like language is learned. Instead, this method is only concerned with providing new knowledge.

The school administration overemphasized this method. It asked teachers to perform this method in any way in case one of the administration evaluation team members visits the class. Teachers were required to do so, even if in a silly manner. It is true that these practices are interesting and require all students in the class to take part in them; however, a teacher should first think about a plan and then include the practice into the plan. Moreover, this should be done for a clear purpose and with intent to achieve the educational goals.

As a result, some teachers had to expand on their goals while others were amazed with students' responsiveness, though not noticing how superficial students' output was. Plus, educational plans were changed in order to suit the administration requirements, and some credits were cancelled as teachers had to suspend them once a monitor was present. Furthermore, limitations were placed on the specific qualifications of teachers, who are supposed to be most experienced in those areas. Instead, practices were imposed on them that in many cases do not satisfy students' needs.

It is not to denigrate active learning strategies by any means, but we believe they should not be regarded as the ultimate goal, particularly if they contradict the course's planned content. Moreover, the school administrative staff should possess the necessary academic knowledge and be completely aware of the needs and requirements of the teaching profession. Staff should also trust teachers, and allow them some freedom to plan for the courses and decide the best practices for students.

Third: The teacher who considers individual differences but strengthens rather than decreases them

No less dangerous than the aforesaid cases, in this case a teacher realizes students' characteristics, levels, tendencies and needs after having them take multiple intelligence tests. The teacher, however, overemphasizes personalization, to the point that he or she makes them more significant instead of decreasing or eliminating them. Although seemingly impossible, this point often takes place.

But how does this error occur? First, the teacher believes he always and in all activities have to consider the individual differences in the same manner, which is absolutely incorrect. The teacher analyzes learners' characteristics at the beginning of academic year and, over the year, premises his work upon his analysis. Based on the common sense, however, this analysis should repeat periodically so as to ensure the real development of students. Moreover, a teacher has to consider the differences in results from time to time, in an attempt to decrease the individual differences. Otherwise, he should be aware that his personalization has some error and should reconsider and strengthen his practices. Because personalization aims to decrease the difference in educational output, it would be wrong not to make any changes in this regard. 
Imagine an eighth grade class in which the teacher considers the individual differences in the writing lesson. To this end, he categorizes students into three levels and realizes that one level is severely weak in phrasing Arabic sentences. In this case, how should he consider the individual differences every time? Imagine he asks the weak group to write simple sentences about a certain topic; asks the moderate group to write long sentences using some conjunction tools; and asks the strong group to write a systematic article about the same topic.

Should he have performed this practice at the outset of academic year, that would be accurate and anticipated. But the problem is when he performs the same method up until the year finishes and makes the exams according to the primary analysis that he performed in the beginning. In this case, students are implicitly requested to remain in the same position, because they possess these abilities and can achieve this goal only. Thus, the teacher suppresses the sense of challenging, competition and creativity but also makes students feel there is no justice and equality between them. How can the teacher explain for the strong student why he has to perform more difficult tasks? How can he explain for the weak student why he denigrated his abilities to this low degree? And what if the latter student was otherwise able to be more creative than the teacher had expected and could perform more difficult tasks? Does not that inactivate student's abilities? Does not that ignore the principle of justice and educational equality between students?

But how can a teacher consider the individual differences and at the same achieve justice and equality?! The teacher has to realize that equality is about rights and opportunities (Rajeh, 1968) and differences concern work and output. However, how does this apply to education?

A teacher should consider the individual differences when teaching a subject to students. He should take into account students' levels, tendencies and talents, but should also provide them with various opportunities to respond to the lesson. That is, they should perceive the information and become knowledgeable, however, the teacher should not determine a certain amount of output for students to produce, either quantitative or qualitative. Instead, the student should be asked to determine the output he can produce, in order for him to be creative within the framework of his tendencies and abilities. When the teacher provides guidance and reinforces the student as best as possible, the highest amount of output can be produced.

\section{Conclusion}

Some believe that all people have multiple intelligence and that anyone can have a high score in any form of intelligence. Therefore, widespread corrections should be made to the educational curricula and teaching methods so they can suit students' tendencies and abilities. In this regard, Gardner's viewpoint has a clear implication:

Not every student is expected to have certain areas of interest, tendencies and approaches that are similar to others', nor is everyone expected to learn everything as there are a myriad of things to be learned.

I would also leave this question open for researchers:

It is naturally impossible for someone to learn everything. Yet he can be creative in an area that suits his characteristics and tendencies. Thus, would it be reasonable for curricula to change such that students become specialized in different fields of sciences and knowledge from an early age and according to their individual differences? And would that speed up the human development process?

\section{Suggestions and Recommendations}

In order for personalization to be effective and not denigrating, and to achieve the desired goal thereof, the following points should be considered:

1. The significance of individual differences between students should be investigated systematically; 
2. The course activities should be diversified and based upon an analysis of students' characteristics, so they suit all levels;

3. More than one teaching method be used;

4. Preliminary, formative and summative evaluations be employed;

5. Students' development be monitored and an attempt be made to consider how successful are the practices that are designed to suit students' individual differences;

6. Students be given an opportunity to systematically boost their abilities and talents;

7. Learners' sense of disappointment be confronted;

8. Justice be applied when providing students with educational opportunities;

9. Students be encouraged to assume academic responsibility by participating in important activities;

10. Teachers' freedom to plan, evaluate and use the academic method be respected;

11. Academic and professional preparation be provided for teachers, administrative staff and all the decision-makers involved in the educational process;

12. Professional preparation change teachers' approaches before changing the practices, in order to benefit the student and improve the teaching profession; and

13. No restrictions be imposed on the student's perspective and no limitations, under the guise of considering individual differences, be placed on his output in case he or she wants to perform and produce more.

\section{References}

Adas, A. R. (2007). Introduction to psychology, Dar Al-Fikr for Publication and Distribution, seventh edition.

Ahmad, B., \& Musa, S. (2019). The differences between males and females in social skills, Journal of College of Education, 30 (117): 603-616.

Dakhl Allah, A. (2015). Theories of learning, Dar Al-Kotob Al-Ilmiyah, Beirut, first edition.

Daum, H. (2017). The most important teaching methods for adjusting to students' individual differences from the viewpoint of physical education teachers, Journal of Educational Sciences Studies, 44, 221-231. https://zu.edu.ly/uploadfiles/file-1557924541077.pdf

Mohammad Kamel, A. W. (1996). Fundamentals of individual differences, Dar Al-Kotob, Cairo.

Rajeh, A. I. (1968). Fundamentals of psychology, Dar Al-Kitab Al-Arabi, Cairo, seventh edition.

Reymawi, M. (1994). Psychology of individual and collective differences in mental life, Dar Al-Shorouk, Amman, first edition.

Sakal, F. R. \& Khalifeh, A. S. S. (2017). Journal of College of Education, No. 7.

Sheikh, S. K. (1982). Individual differences in intelligence, Dar Al-Thaqafa, Cairo, second edition.

Suleiman, M. T. S. (2009). Classroom management, authored by Paul R. Burden, University Book Publication, Gaza, Palestine, second edition.

Surah Ar-Rum, Verse 22, the Noble Quran. 